\title{
C. R. EHRSTRÖM OCH BRAHESTAD - ETT STYCKE FINSK MUSEIHISTORIA
}

\author{
Janne Vilkuna
}

Finlands generalguvernör Peter Brahe (1602-1680) främjade Finland på många sätt. Han grundade Åbo Akademi 1640, ett eget postverk och nio nya städer. En av städerna var hamnstaden Salo i Österbotten 6 mil sydväst om Uleåborg (grundad 1610) som grundades 1649. Staden fick sedan namn Brahestad (Fi. Raahe).

Brahestads "storhetstid» var ca 18551875 när stadens handelsflotta var Finlands fjärde i storlek och stadens handelsmän samlade förmögenheter. Stadens invånare gjorde som sjöfarare bekantskap med fjärran land och hemförde många slags nyheter, kuriositeter och märkliga berättelser.

\section{FINLANDS FÖRSTA KULTURHISTO- RISKA SAMLINGAR OCH MUSEER}

Vid Åbo Akademi började man 1721 bygga upp en mynt- och medaljsamling. Sedan tillkom också en naturaliekabinett, porträttsamling och fornsakssamling.

Apotekaren i Uleåborg Johan Julin (1752-1820) hade en naturhistorisk samling som han visade för publik. När han flyttade 1814 till Åbo skänkte han en del av samlingen till akademin där. Den andra delen ärvde sonen, apotekaren och skepps- redaren Erik Julin (1796-1874), men båda hans och akademins samlingar förstördes i Åbo stadsbrand 1827. Julin började samla igen, men nu främst kulturhistoriska, etnografiska och biologiska objekt från norra Stilla havet och dessa skänktes 1852 till Åbo gymnasium för att bli ett offentligt museum (efter en lång lagring öppnades samlingarna på nytt 1960).

Efter stadsbranden flyttades akademin till Helsingfors, där Kejserliga Alexander Universitet i Finland fick sina statuter 1828. Enligt statuterna hade universitetet bl.a. ett astronomiskt observatorium och en instrumentsamling, en botanisk trädgård, ett zoologiskt museum, ett kemiskt laboratorium och ett mineraliekabinett, ett kabinett med fysiska instrument och ett mynt-, medalj- och konstkabinett. Det sistnämnda innehöll också etnografiska objekt som skildes ut 1849 då ett etnografiskt museum blev till.

Finland fick en fornminneslag 1883 och nästa år grundades arkeologiska kommissionen (omorganiserades 1972 till Museiverket) som leddes av en statsarkeolog. År 1893 förenade staten universitetets etnografiska museum, studentkårens etnografiska museum (grundat 1876) och Finlands fornminnesförenings (grundad 1870) sam- 
110 lingar och arkeologiska kommissionens samlingar till Statens Historiska Museum som arkeologiska kommissionen förvaltade. När museet fick sin nybyggnad, som öppnades för publik 1916, blev museets namn Finlands Nationalmuseum.

Brahestads museum grundades av Carl Robert Ehrström 1862 som Finlands första lokalmuseum. Uleåborgs tidnings redaktion som publicerade det finskspråkiga museimanifestet, uttryckte $\mathrm{i}$ ett redaktionellt tillägg en önskan om att andra dylika museer borde grundas. Den förblev dock ouppfylld och Brahestads museum var länge det enda lokalmuseet. Inte förrän 1881 grundades nästa museum, Åbo stads historiska museum, men sedan gick det snabbare och vid sekelskiftet fanns det redan 13 lokalmuseer av vilka 12 var belägna i städer.

\section{CARL ROBERT EHRSTRÖM}

Carl Robert Ehrström föddes 1803 som son till kapellanen i Kronoby, Anders Ehrström. Fadern hade naturvetenskapliga intressen, vilket hängde ihop med att han hade studerat i Upsala under Linné. Sonen Carl gick skola i Vasa trivialskola, där hans klasskamrat var Johan Ludvig Runeberg. Ehrström fortsatte 1822 sina studier vid Åbo Akademi och - efter stadsbranden - 1828 i Helsingfors tillsammans med Runeberg där de gjorde bekanskap bl.a. med andra kommande nationens stormän som J. V. Snellman och E. Lönnrot. Ehrström fick magister graden 1831, började sedan studera medicin och förvärvade medicine kandidat- och licentiatgraderna resp. 1834 och 1838. Han arbetade först som läkare vid Helsingfors förlossningslasarett. En epidemi där gav

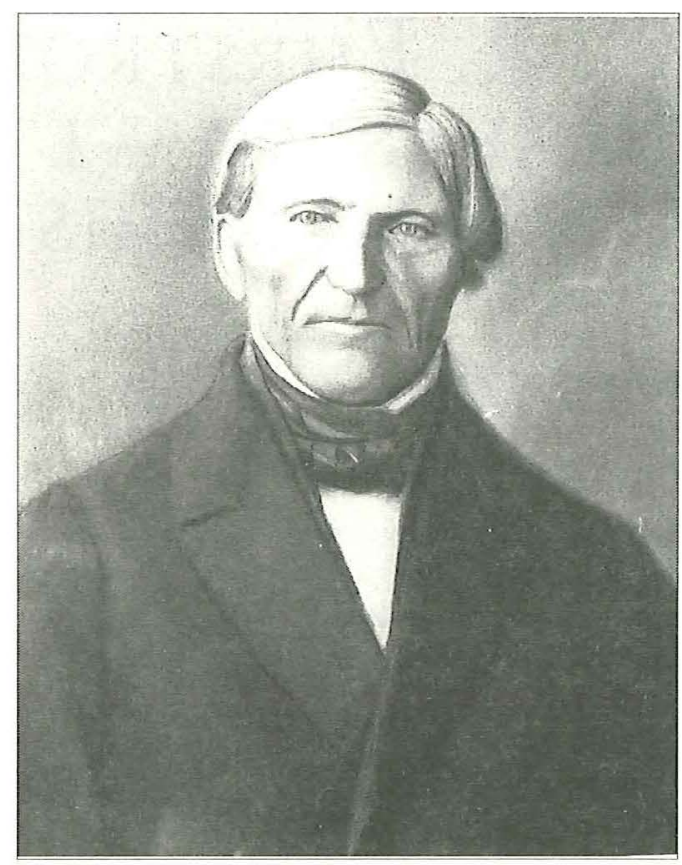

Carl Robert Ebström 1803-1881, teckning efter fotografi. Foto Juhani Ahola. Brahestads museum.

honom ämne till en avhandling som publicerades 1840. År 1838 hade han valts till stadsläkare i Torneå och nästa år till distriktsläkare. I den befattningen gjorde han bekantskap med en stor del av Lappland. År 1854 flyttade Ehrström som distriktsläkare till Brahestad, där han arbetade till sin pensionering 1871 och stannade till sin död 1881 .

Ehrström var aktiv med i många lokala sociala uppgifter, men också i nationella projekt och han brevväxlade bl.a. med Lönnrot, Snellman och M.A. Castren (senare första professor i finska språket). 
Han gjorde själv endast en utlandsresa 1844 - till Tyskland och Österrike.

Den 4 april 1862 sände Ehrström ett insamlingsbrev till Brahestadsborna för att tigga medel för det kommande museet. Hela stadens bildade klass var med på saken. Med de insamlade medlen skaffade man vitrinskåp. Redan 1862 donerades 248 föremål, mest numismatik, men samlingen fick en mycket exotisk prägel i denna hamnstad. De första naturhistoriska och etnografiska föremålen var bl.a. en uppstoppad kameleont och flamingo, ett strutsägg, en sköldpadda, ett kinesiskt

"Den Gamla Herrn", frain 1700-talet, "världens äldsta dykardräkt». Foto Juhani Abola. Brahestads museum.

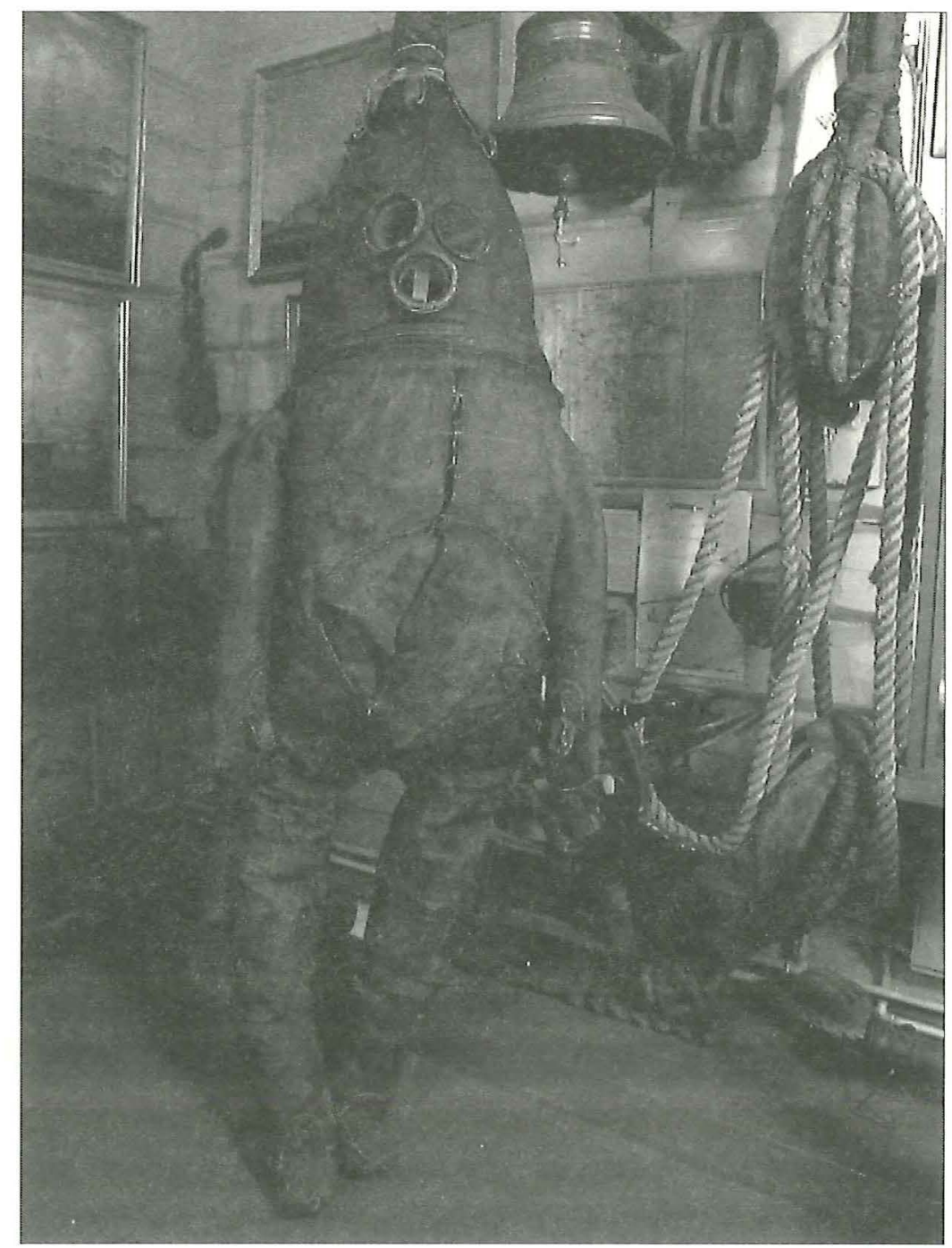


112 parasoll, en indiankanot från Kanada och en sten från en kolonn i Pompeji.

Ehrström skrev under sitt museipolitiska manifest 21 oktober 1862 på svenska och det publicerades i Uleåborgs tidning, Oulun Wiikkosanomat, 8 november på finska. Manifestet visar klart sin skrivares lärdom och intelligens. Det är ännu aktuellt idag när man kräver att museer skall vara med i samhällslivet och betonar museets pedagogiska funktion.

Museet fanns först i Ehrströms hem, men placerades $1865 \mathrm{i}$ ovanvåningen till stadens tull- och packhus (byggt 1848). I bottenvåningen fanns handelsföreningen och sjömanshuset. Ehrström skötte museet ensam till 1879 då stadsnämnden förordnade stadsläkaren Frans Neovius till hans hjälp.

\section{BRAHESTADS MUSEUM EFTER EHRSTRÖM}

Ca 1870-1897 var museet i stadens skola och rådhus. Museiverksamheten tynade i någon mån efter Ehrströms död, men sedan tog staden eget ansvar för museet, som 1898 åter började arbeta aktivt. Men nu riktade man uppmärksamheten på insamling av lokala föremål.

När handelssjöfarten påtagligt hade minskat, överlämnade handelsföreningen 1893 packhuset till staden och museisamlingen flyttades in ca 1900 tillsammans med stadens bibliotek. När biblioteket sedan flyttade 1960, fick museet hela huset (385 m2). Ar 1989 hyrde staden det äldsta bevarade bostadshuset (byggt på 1780 -talet, $378 \mathrm{~m} 2$ ) till museet och museets kansli. Där placerades även lokaler för tillfälliga utställningar. När staden fyller 350 år 1999 skall också ett interiörmu- seum som visar ett köpmans- och skeppsredarehem, öppnas i huset. Museets magasin är från år $1852(1500 \mathrm{~m} 2)$.

Brahestad fick en kommunal kultursekreteraretjänst 1967 som också skötte museet, men 1985 inrättades en särskild amanuenstjänst, 1991 en konservatortjänst och 1998 en förvaltaretjänst för museets arkiv och magasin.

Museets dokumenteringsansvar är numera livet i Brahestad. Samlingarna består av ca 30000 museiföremål, 15000 bilder samt arkivmaterial. Samlingarnas pärla härstammar emellertid från Ehrströms tid, nämligen föremålsnummer 61 som är «den Gamla Herrn», "världens äldsta dykardräkt» från 1700-talet. Den skänktes av sjökapten Johan Leufstadius. Den är gjord av kalvskinn och är troligen av inhemsk tillverkning (handskarna och stövlarna är av typisk finsk modell). En kopia, "Unga Herrn», tillverkades och prövades med framgång 1988.

Brahestads museums avdelning $\mathrm{i}$ packhuset, med bl.a. de utställda "exotiska» föremålen är i högsta grad ett stycke finsk museihistoria - ett museimuseum!

\section{$K \ddot{A L L O R}$}

Drake, Knut. Forntid Nutid Framtid, Abo stads historiska museum - Abo landskapsmuseum 1881 1981. Åbo 1995.

Hans Kejserliga ... Statuter för Kejserliga Alexander Universitetet i Finland, 1828 Den 28 November.

Härö, Mikko. Suomen muinaismuistohallinto 18841917. Helsinki 1984.

Jokipii, Mauno. C. R. Ehrström-suomalaisuusmies ja museoaatteen uranuurtaja. Osma 1962-63. Helsinki 1964. (Deutsche referat) 
Knapas, Rainer. Yliopistonrakennukset Turussa vuoteen 1809. Kuninkaallinen Turun akatemia 16401808. Helsingin yliopisto 1640-1990 Ensimmäinen osa. Keuruu 1987.

Nikander, Hagar. Ett skolmuseum [Erik Julins samling]. Osma 1962-63. Helsinki 1964.

Stenfors, Piia. Raahen museon antiikkikokoelma. Oulun yliopiston yleisen historian pro-gradu 1994.

J.[enny] M.[aria] T.[allgren]-M.[ontin]. Raahen museo. Suomen maaseutumuseoita (toim. A.M. Tallgren - E.A. Virtanen). Jyväskylä 1920.

Tallgren, Jenny Maria \& Levón, Kaarlo. Raahen museo. Suomen kulttuuribistorialliset maakunta- ja paikallismuseot. Helsinki 1932.

Jag tackar Brahestads museums amanuens, Eija Turunen, för uppgifter om museets nuvarande förhållanden.

Janne Vilkuna är en av redaktörarna för Nordisk Museologi och verksam vid museologi, Jyväskylä universitet. Adr: Museologi, Jyväskylä universitet, Box 35, FIN-40351 Jyväskylä

Fax +358-14601461

e-mail:jvilkuna@campus.jyu.fi 